\title{
Emotions in Business-to-Business Service Relationships
}

\author{
JULIA A. KIELY
}

\begin{abstract}
Emotion in business-to-business service relationships regarding cargo services is explored. The service relationship is characterised by mutual trust and cooperation. Contact is mainly via telephone or e-mail with some face-to-face interactions and participants providing a complex, multi-skilled seamless service. Experience rather than training plays a vital role with long-term service relationships built up and maintained. Emotional sensitivity is acquired partly by experience and a repeat customer base but mainly through a genuine desire to help and get to know others. In contrast to the view of emotional labour bringing managerial control or adverse affects to service staff, the emotion engendered by this work is authentic expression bringing personal satisfaction.
\end{abstract}

\section{INTRODUCTION}

Emotions in service encounters have attracted considerable research attention in recent years. Increasing numbers of service encounters are virtual service through the replacement of people with technology. Efficiency, standardisation of service and cost imperatives drives the rise in call centres. Large numbers of customer service jobs have become de-skilled as companies strive to benefit from mass consumption. From a managerial perspective, emotions are seen as potentially irrational or illogical, with the potential to disrupt organisational outcomes if not managed. Those in positions of power or dominance see it as their right to control and groom emotions with a view to enhancing customer service. Emotional labour, as perceived through the eyes of jobholders, and tangible outcomes in terms of turnover and stress has also been subject to much scrutiny.

While the changing nature of service interactions between staff and the general public has been extensively explored, commercial encounters and business-tobusiness interactions have been largely ignored. This study explores emotions in commercial service transactions between shipping agents, shipping lines and port authorities with regard to cargo services. As in many customer service settings, much of the contact is via voice-to-voice, e-mail or written correspondence with

Julia A. Kiely is at the Business School, Bournemouth University, Christchurch Road, Bournemouth BH1 3LH, UK.

The Service Industries Journal, Vol.25, No.3, April 2005, pp.373-390

ISSN 0264-2069 print/1743-9507 online

DOI: 10.1080/02642060500050517 (C) 2005 Taylor \& Francis Ltd. 
some face-to-face interactions. In contrast to many other service settings, the encounter takes place in the context of broader and longer-term service relationship. The term 'service relationship' signifies an interaction where customer and service provider get to know each other over time as role occupants, in contrast to one off service encounters [Gutek et al., 1999]. In the present study, those handling interactions move freely between the different communication media, providing a multi-skilled seamless service. While some service interactions involved in this setting might be amenable to standardisation, most are not. Nor is it perceived desirable to do so. Variety, unpredictability and implicit knowledge acquired through many years of experience characterise many encounters. The operations taxonomy of professional service [Johnson and Clark, 2001] characterises the encounter - low volume of customers balanced with high contact time, flexibility, customisation and discretion. It also shares characteristics of an artisan service [Sturdy et al., 2001: 107] in calling for special skills tailored to the customers service needs. The rich, complex web of service interactions and exchanges helps promote and retain repeat business. The service interaction, though, is fraught with the potential for anxieties and problems. Trust and confidence in the other party, together with an element of unpredictability underlies this service. The potential for mishaps is rife and at times overt emotions such as anger run high.

This research seeks to uncover ways in which customer service staff interpret and manage both their own and customers' emotions in business-to-business relationships relating to cargo services and the impact of emotion on job holders. It endeavours to capture the experienced reality of emotions and reveal the complex part they play. The study is focused on the Ports of Vancouver, British Columbia Canada and Poole Harbour United Kingdom. The Port of Vancouver, British Columbia handles 70 million metric tonnes of cargo and facilitates trade with over 90 nations. In contrast to Vancouver, Poole Harbour Dorset is a small busy commercial port handling cross channel ferries and cargo vessels. Poole is a major port for bulk cargo imports and one of Europe's largest on-shore oil fields is under the harbour. Increasing numbers of service relationships are cross-national while national populations are themselves diverse. Focusing on two ports in different geographical regions provided the possibility of exploring subtle national differences in ways in which emotion in these settings is perceived or managed.

\section{LITERATURE REVIEW}

The increasing importance of the service sector in world markets over the last 25 years has led to a growth in research devoted to this area. Attention has focused on the customer-service provider interface with the business-to-business interface attracting relatively little attention. Service quality and satisfaction has been traditionally conceptualised and measured as a cognitive disconfirmation of some comparative standard or expectation 'gap' [Gronroos, 1984, Parasuraman et al., 1985, 1988; Liljander and Strandvik, 1996]. The assumption behind early research is that good quality service or meeting customer expectations invokes customer satisfaction. 
Developments from this strand of research has explored roles and behaviours expected of service staff from customers [Goleman, 1995, 1998; Kruml and Geddes, 2000] with the implicit assumption that an appropriate match leads to customer satisfaction. From the perspective of role theory [Broderick, 1999] elements of service, including dyadic interactions, are explored. These studies are united in consistently failing to undertake a reasonable appraisal of the meaning and significance of emotion in service relationships. The importance of this deficit is underscored by the commentary of recent authors, who emphasise the role of emotion in the broader workplace [Fineman, 1993, 1996, 1999; Ashforth and Humphrey, 1995; Domagalski, 1999].

Initially, the predominant research focus in service encounters was very cognitive in nature with the consumer actively considered to be processing the perceived performance and comparing it with some standard [Mano and Oliver, 1993; Richins, 1997]. The implicit assumption in this comparison, regarding levels of satisfaction and service quality being related symmetrically, has been challenged. Service quality below expectations appears to have a greater impact than when service is exceeded [Zeithaml et al., 1993]. Moreover, research has shown that the cognitive component of a service interaction is influenced by the affective component [Liljander and Strandvik, 1996]. Nonetheless, while affect has emerged as an important theme in service interaction [Oliver, 1993; Price et al., 1995] the relationship between cognition and satisfaction is far more often investigated [van Dolen et al., 2001].

Research in the field of emotions has reached a level of maturity whereby it is possible to see distinct trends. One branch of literature focuses around the theoretical grounding of emotion. Emotions are often defined, both in professional and lay psychology, in contrast to cognition and rational thought [Edwards, 1999]. They are seen as naturally occurring bodily experiences, expressions and feelings rather than thoughts. Emotions are not only contrasted with cognition but there are also cognitive theories of emotion and indeed emotion-based explanations of cognition. For instance prejudice could influence what people think about a service encounter. Emotion can be described in physiological terms as an individual's response to stimulus. Others see emotion from a predominantly social interaction perspective. Here emotions are understood to be responses to outcomes of social interaction which are 'essentially positive or negative in nature, involving direct somatic (and often) cognitive components' [Kemper, 1978: 47]. As outcomes of social interaction they are, to a degree, socially constructed and hence amenable to social influence by situational variables. Shaping the interpretation customers make may influence the emotions they feel [Locke, 1996].

Menon and Dube [2000] take the stance that emotions are the affective responses to one's perception of the series of attributes that compose a product or service performance. Such emotions are usually assumed to be intentional in that they have an object or reference point. Bagozzi et al. [1999] conceptualise emotion as being distinct from generalised, diffused and non-intentional states such as mood. Indeed, Bagozzi et al. [1999] consider emotion, mood and attitude as elements of a general category of mental feeling processes, referred to as affect. In line with other writers 
[Strauss and Neuhaus, 1997; Yu and Dean, 2001] they have explored connections between emotion and behaviour. Others, such as Fineman [1993] see emotion from a social constructionist viewpoint with the notion of emotional contagion [Hatfield et al., 1994] providing evidence that emotions are social in nature. Emotional contagion, the interpersonal view of emotion [Parkinson, 1995] and the work of Menon and Dube [2000] provide additional insights in their discussion on how some emotions trigger an instinctive 'mimetic' response while others induce a complementary response. Notions of reciprocity are also pertinent here. The experience and expression of a specific emotion may be accompanied by explicit expectations of interpersonal responses that help the person manage or cope with emotions. For instance, showing annoyance or impatience with an issue may be accompanied by an expectation that the other party will take action to resolve or smooth the issue.

The view of emotion as visceral and physiological changes experienced by individuals is one that can be contrasted with the socially/interactionally produced phenomena. The latter perspective, drawing a distinction between the subjective experience of emotion (feelings) and their personal display (emotions) is the approach adopted in the current study. This study takes the view that emotions are the responses to outcomes of social interaction and are socially constructed. Issues of emotional contagion and emotions influencing interpretations of social interactions and vice versa are also pertinent.

Since Hochschild's [1983] seminal study, one branch of literature has focused on 'emotional labour' involved in service delivery and the management or regulation of feelings. In a service context, this typically is taken as ensuring the customer feels good about the encounter. Hochschild [1983] distinguishes between 'surface acting' and 'deep acting'. In 'surface acting' emotions are feigned while in 'deep acting', and authentic expression, genuine emotions are displayed. Emotional labour can be differentiated according to whether the employees or customers feelings are the focus of attention and the effect of emotional labour on those who perform it. Jobs involving emotional labour are largely those requiring contact with other people, external to or in the organisation, usually involving face-to-face or voice contact. While this type of interaction is frequently found in service organisations, it is by no means exclusive to it.

Two distinction strands of research have emerged from Hochschild's study. The first pertains largely to qualitative case studies of emotional labour seen through the eyes of jobholders. employees in workplaces in the service sector. Emotions are perceived as potentially irrational or illogical, with the potential to disrupt organisational outcomes if not managed. Ways in which those in positions of power or dominance control the displayed and felt emotions of employees in the interests of organisational goals by recruitment, socialisation and training [Domagalski, 1999; Morris and Feldman, 1996] is examined. Researchers taking a managerial stance [Rafaeli and Sutton 1989; Kunda, 1992] have discussed formal and informal norms required of employees. They argue that understanding emotion helps employers recruit appropriately socialised individuals and affects key areas such as customer behaviour and organisational productivity. 
Leidner [1991] found many employees in the service sector had highly routinised scripts they needed to follow, thus extending managerial control to aspects of work not formerly subject to intervention. Employee resistance was less than anticipated leading her to conclude that conflict between labour and management takes on a third dimension - that of customers. Management and employees develop the same objectives towards customers with scripted emotional labour helping employees manipulate customers while at the same time distancing oneself from this performance. Implicit in these studies is the influence of cultural norms on selecting the appropriate person to perform different jobs. A separate and distinctive strand of ideas relates to Emotional Intelligence. Popularised by Goleman [1998], critics argue much of this work relates to competencies and adds little new [Davie et al., 1998; Eisenberg et al., 2000; Woodruffe, 2001]. Interpersonal and personal skills and cognitive abilities have long been acknowledged as important while emotional intelligence dimensions can be indistinguishable from the competencies they are meant to cause. Nonetheless, competence in emotional intelligence is a prerequisite for all types of service work.

A second overlapping strand of research focuses more on emotional labour in different settings or nurturing activities and its consequences for employees in terms such as pay, productivity, fatigue or job satisfaction. These studies tend to be predominantly quantitative, exploring the negative consequences of emotional labour for employees, including burnout, stress and fatigue. Such research embraces felt mood or emotion versus publicly displayed emotion and emotional dissonance [Morris and Feldman, 1996], the dimensions of emotional labour, their intensity and variety. Schaubroeck and Jones [2000] suggest that demands to display positive emotions or suppress negative emotions have different effects on individuals and vary according to their degree of job or organisational identity. Surface acting and the requirement for employees to suppress, subjugate or manage their own emotions while caring for or managing the emotions of others was considered to have potentially negative consequences. However, as shown by Wharton [1993] and Wharton and Erickson [1995], this is not necessarily the case. Emotional labour does not have a uniform negative impact on job satisfaction. Wharton [1993] suggests job involvement and autonomy may affect whether or not employees experience emotional exhaustion. She concludes that, while there are negative psychosocial consequences under some circumstances, jobs requiring emotional labour may have a positive effect on workers' well being. When all else is equal, workers find jobs involving emotional labour more satisfying than comparable jobs that do not involve this activity. Furthermore, many jobs do require 'emotional work' in that they necessitate smoothing out tensions or helping work colleagues [Steinberg and Figart, 1999]. Emotional work is defined as behaviours performed to improve emotional wellbeing in others and to creative cooperative and positive social relationships [Strazdins, 2000].

The 'invisible' nature of much emotional labour and emotion work has been considered a factor in the consequent lack of remuneration for the competent performance of such skills. While this may have a bearing, emotional labour has stereotypically been associated with female jobs. Despite legislation there still 
tends to be a pay gap between the sexes compounded by 'female' jobs such as catering and 'caring professionals' such as nursing tending to attract lower pay in relation to alternative careers. Permeating much research in this area is the gender nature of emotions [Parkin, 1993] with females consigned to the expressive sphere and males to the dispassionate sphere of reason.

Research exploring the future roles and capabilities of customer service staff underscores the importance of mix of abilities - emotional interaction for managing relationships and technical processes for fact-finding activities [Armistead et al., 2001]. Emotional interactions affected every stage of most services and formed the lasting memories for customers of good or bad service. Customer service managers describe the need for all service staff: to identify and understand their own emotional reactions and those of customers, to control their emotions, to use emotion to make good decisions and to act effectively. Words such as 'empathise' and 'give from the heart' permeated perceived future requirements in settings verging on mass service. Participant organisations were, however, unable to articulate what they meant by such terminology and descriptions, or how these requirements were accomplished on a routine basis. Terms such as emotional intelligence were used with the assumption of a commonly understood definition implying competencies - which there is not. The importance of emotion shone through but what it meant was opaque.

In their different ways, these various strands of research provide indirect observations regarding emotion in service relationships. The concentration of research has been on service encounters in mass service operations such as call centres, characterised by high volume of customers, short contact time and little service discretion. There has been a tendency to explore how organisations shape and control emotion in the interests of achieving organisational goals, with the implicit assumption that this remains a managerial prerogative. The view that skilled emotion management of dayto-day issues may benefit jobholders or indeed be a part of the job that causes satisfaction has been largely overlooked. Similarly, the possibility that customer service staff may use emotions in ways that advantage themselves rather than their organisation has not been considered. It is these areas the research seeks to explore.

\section{RESEARCH STRATEGY AND DESIGN}

An interpretative stance is taken in the research with the emphasis on elucidating meaning rather than producing cumulative generalisations. Interpretation and awareness of emotions displayed by customers in service encounters is relatively easy to assess in extreme cases or when the service encounter is face-to-face. The environment in which the research is set is one where many service encounters are voiceto-voice, which limits the transfer of sensory information and its interpretation. In written communication, including e-mail messaging, emotion has to be interpreted through language alone. Customers can craft words to reflect or imply particular emotions; similarly, service providers can deploy words to deflect or remain 
emotionally neutral. This research specifically focuses on the more subtle forms of emotion which are harder to detect and respond to.

Representatives were selected in order to get a cross-section of business-tobusiness service networks relating to cargo/container services. Three groups of respondents were interviewed: shipping agents; shipping lines and port authorities, and 12 in-depth interviews were undertaken. Care has been taken to ensure all material included in the analyses is anonymous, unattributable and conforms to ethical research guidelines. Shipping agents are identified as A1-A5, respondents from port authorities as P6-P9 and those from shipping lines as S10-S12. All interviews took place in May/June 2002. One person preferred not to be taped and in that case detailed notes were taken and typed up. All other interviews were taped and transcribed. Following transcription, each interview was read through many times in order to develop a template for thematic coding. Given the social construction perspective taken in this research, template analysis is an appropriate epistemological stance. The final stages of data analyses were undertaken using a qualitative data analysis package. This helped facilitate regrouping and redefinition of individual codes and multiple coding prior to developing general higher order codes containing clusters of similar concepts. In addition to interview data, examples of written data were sought which respondents were willing to talk through and share. Examples ranged from circulars and letters to e-mail correspondence.

\section{THE FINDINGS}

\section{Communication and the Work Roles}

Shipping agents represent the ship owners on the ground in the port. It was described as a communication and coordination role. Respondents described their role as 'an inbetween party' (A3), 'piggy in the middle' (A1), 'bringing the people together that can get things sorted out' (A5). It involves keeping everyone advised to minimise port time and looking for all the information that is needed from the ship. Most of the correspondence relates to loading, unloading and processing.

The problems are immediate, you can't, we can't waste time considering it ... you have to either discuss it on the phone or put it in an immediate form like fax or email. (A1)

The work was described as not an easy job with long, unsociable or flexible hours requiring them to be a 'jack of all trades' (A3):

everything can change in just a second ... shipping is so unpredictable and ... you just can't really get upset about changes and stuff because you're just in the wrong business if that's the case because that's what its all about. (S5)

Individuals not fully appreciating, or choosing not to appreciate, the terms of reference of agents could raise difficulties. Captains may want to incur expenditure agents have not been authorised for or shippers may want agents to make decisions 
on matters where they are not empowered. Agents had to be both attune to this and sensitive to how they handled these situations.

The shippers here often tend to view the agent here as the first party forgetting he is really only carrying out the instructions of his principal - which is the shipping line. (A3)

Agents themselves were aware of the need to 'make sure you've got the responsibility of the owner' (A1). Any serious problems require them to go straight to the principal for instructions.

No matter how much rope and how long a leash you operate on that what it all comes back to. You know its what does the principal want? (A2).

We have to sort of say 'OK, we're the boss, you need to talk to us about this and not be going to anyone else' but you also have to tell them in such a way that you're not going to cause a problem for the next time. (A5)

'Next time' alluded to much of the work being repeat business. Agents have dealt with some principals for years and many of the ships come in on a regular basis.

Coordination plays a key role in the work of those at the port authorities be that coordination of port operations problems and infrastructure or overseeing marine operations. The dynamic, changing nature of the work was apparent.

You're just picking it up at one point, taking it to a point and letting it go but its still going. (P6)

Who they perceived as their customer varied according to their role in the port.

... recognise that the deep-sea ships are our customers - not necessarily the exporter who may be shipping cargo - but the ship itself and its officers, staff and agents. (P8)

The latent power of main customers was recognised together with the need to be impartial.

... uunderstanding of where they are coming from and what the consequences are of really upsetting them would be to this port ... we cannot be seen as promoting one against another. (P7)

In line with all other groups of respondents, those at the port authorities considered that '95\% of what I do is go with people and issues and work through those things' (P8).

Those interviewed from the shipping lines were responsible for running offices making sales booking or selling space on container ships. High proportions of customers were repeat customers. Communication was again largely immediate by telephone or fax/e-mail. Much of the documentation and communication was seen as not subjective (S11) but respondents did have to deal with the emotion of customers.

The cases where we find people are a little bit irate or impatient is when our ships ... one example would be when our ships are full - over booked and 
there is no more space and they phone to make a booking and we say 'Sorry we can't do' and they say 'It just one container - can't you squeeze one container on?' and we say 'No because if we do this for you other people may phone and the same thing may happen. (S12)

Practically all those interviewed had worked in the shipping world all their lives. Some had been in the industry for over 30 years. Those who worked for them had, by and large, many years of shipping experience 'the average is $12-14$ years that's good' (S12). One respondent mentioned that the six people working in his office had close to 200 years' experience between them. Those with whom they dealt likewise had many years of industry specific experience. This facilitated understanding of others jobs and what was and was not feasible.

... and I know how much they can do. Because although they are a government agency, they can't handle everything by themselves. So sometimes I am more tolerant of such things. (S10)

\section{Communication Type and Emotion}

Telephone, e-mail and fax, in that order, were the most frequently used communication mechanisms for shipping agents and shipping lines, with some face-to-face contact. Respondents also had laptops and cellular telephones for out-of-hours communication. Informal and cooperative were frequent communication descriptors. The port authorities spend slightly more time in face-to-face communication.

While up to 80 per cent of communication was classed as 'standard' or 'routine' by shipping agents and shipping lines, building relationships and trust with those with whom one was in correspondence formed a major part the work. This influenced the wording of correspondence and the form it took.

I don't have a standard layout, I do them on an individual basis but in actual fact you could put something in as a standard, probably come up with a 25 or 30 line standard and then just modify it for each ship. (A3)

One of the shipping agents described it as:

We send a quick email and talk about football, soccer or what ever is coming up, the World Cup and that and then we get to more problem solving. (S12)

Another expressed the same sentiment but the order differed. This could be due to cultural differences, although not too much should be read into it this without further evidence.

Especially when you've been dealing with these people for quite so long . . first of all business is business and we have friendship inside. (S10)

With those with whom respondents had regular dealings 'they let you know if they are upset' (S5) while with someone they did not know so well, or who perhaps had English as a second or third language, picking up on emotion was harder but an essential skill: 'if you can't pick up some of the subtleties you are treading on thin ice' (P8). 
The artisan aspects of the work [Sturdy et al., 2001] and professional service [Johnson and Clark, 2001] both characterise the roles played and highlights the advantages of this form of customer service. With around 80-90 per cent of the work's repeat business with the individuals or company base, relationship-building is crucial. For some agents, 20 per cent of their customer base gives 80 per cent of their cargo so good working relationships with the customer are essential to stay in business. Many viewed with some trepidation or disdain the trend of centralisation in shipping.

It's a lack of personal touch but I think the big corporations have made a conscious decision to sacrifice, to compromise would be a better word, to save some money. (P6)

One respondent described their web page as 'one size fits all' but emphasised that they quote each person individually and that each account is tailored to the needs of their client. Areas like tracking business can be done via web pages but 'most people still prefer to phone up'.

... that local contact local sales forces provide ... more additional value ... maybe even a dollar or two dollars more on the rates. But I don't know how long they'll be buying that ... That's why I'm not too keen on centralisation because I don't think you can build the relationship with the person. (S12)

One person mentioned that if someone observed people working they might be amazed by how often people lose their temper and there is a strained atmosphere because of it as it is an industry where lots of things can go wrong (S11). The form of emotion varied from the obvious emotion of angry words and having ones parentage called into direct question to 'got really nasty with me' (A3) to those who displayed emotion in 'a more professional and refined way' (P8). Respondents found it relatively easy to pick up emotion and feelings in face-to-face or voice communication.

What you hear is part of it, what you see when you hear is the other part of it and even a telephone, at least you hear something you get inflections. Whereas e-mail you don't get that at all, its just the words that are used. (P6)

Personal knowledge, experience and understanding of the communicator sensitised the recipient to affective or cognitive messages in the communication. Telephone or other personal contact was considered the most appropriate way of reconciling issues as the message sender was usually known personally.

Emotion in written communication was seen as harder to detect accurately unless the writer had specifically intended the message to be interpreted in a particular way. As one person said, 'half the problems are never as big as they appear in print' (P7). While email allowed more time for a considered response to emotionally charged situation than telephone, it was important to avoid 'the knee jerk reaction ... send of a poorly worded message (A4)' and inflaming the situation. Another said 'there is not everything you want to put in print' (P9). 
The benefits of knowing people personally, or by reputation, reaped huge benefits in dealing with potentially difficult issues where emotions could run high.

So everyone knew everybody ... so there was a level of trust that allowed the decision to be made. (P8)

\section{Emotional Contagion and Reciprocity}

The effect of emotion and its aftermath on respondents was sought. Having to appease the customer as best they can together with the attitude that 'the customer is always right - even when they're wrong' (S12) was an ingrained reaction. Inevitably negative emotion upset respondents but there was a general view that 'you've just got to let it wash over you' (A1) and 'be thick skinned' (P6). This did not mean that respondents did not care or that they were 'surface acting' [Hochschild, 1983]. It was an acknowledgement that when they had done everything they could, that was all that could be expected. They should not take any negative reaction too personally although it could be hard to block out: 'it grinds at you' (P8).

He's been in the job for 12 years and he's taking it on the chin but he does get quite uptight and upset about it. (A1)

The view 'when you know you've tried your best with no regrets, that's fine' (S10) summed up several respondents thoughts.

Having to break bad news to customers or not being able to satisfy customers requirements genuinely upset respondents.

Especially if its someone, you know, you've dealt with for a long time and you really want to be able to help them but you just have to understand there are limitations ... much as you try and do your best, it just isn't going to work out ... I've been doing it for a long time and I still don't like it when I have to tell the people (bad news). Or ... if it's a good customer of mine or I know the person I ensure I phone him myself ... It's not a good feeling (S12).

The 'lows' of not being able to help customers or of taking the blame for problems not within their control - while unpleasant and causing strong emotional feelings in respondents - were far less frequent than the highs. Respondents spoke with enthusiasm of the good feeling from doing a good job, seeing a ship go out fully laden and knowing you were responsible for avoiding a catastrophe.

It's a good feeling to know that you sorted it out or you avoided a catastrophe yeah its nice to know that. You know, you're able to sort of smooth things over. (A5)

That's pretty good, I made that happen. I mean you didn't really but you make sure the ships in the right place and the right cargoes went on board, yep a bit of a high. (A4) 
It's the people and it's not just the crew on the ship, but it's the other people from ashore that are on the ship as well, you're working on it and that's what makes the whole thing go round and worthwhile. (A2)

From these quotations it is apparent that the job itself brings out strong feelings of emotional satisfaction in the work. A large element of 'emotional labour' is involved in the work. But the 'emotional labour' had a totally different impact on respondents to that commonly assumed in the literature. It was what made the job worthwhile and kept them in the shipping world. The 'buzz' and 'dealing with people' was considered 'what keeps them going'. Planning everything correctly, getting the ship loading and discharging with out incidents, going on board and establishing or reestablishing working friendships and seeing the ship sail away was extremely satisfying. Those working in port authorities similarly gained emotional satisfaction from their work.

I thoroughly enjoy interacting with and dealing with people and I mean I guess seeing initiatives through and dealing with people to see them through ... its great, its what I live for ... knowing that something that was potentially chaotic turned out exceedingly well. (P8)

Occasionally respondents did resort to 'surface acting', but this was rare.

You shake their hands and say goodbye and 'we'll see you again' but that's not what you're thinking 'hope I never see you again'. (A2)

By far the predominant feeling was that of authentic expression. Respondents genuinely cared about what they did and wanted to ensure everything went smoothly. When things went wrong it did upset them.

Positive feedback did have a reciprocal effect.

I go and tell them so they are happy and when they hear that they may even take it one step further when that person phones back another time and they'll remember ... this is the guy that said we are doing a good job.(S12)

\section{What Makes the Job Work?}

Experience and a genuine liking for people and ability to get on with people are key aspects. The job of agents involves a degree of 'selling knowledge' (A2) but 'its not all about being warm and fuzzy' (A5). Knowing 'the rules' (A3) and what needed to be done, being connected and knowing 'the people to talk to' (A5), and being able to make decisions and communicate with others verbally and in writing is critical. Being patient with the problem, common sense, an ability to listen and an ability to develop rapport were all frequently mentioned. So were adaptability, resourcefulness, knowing when to empathise, sympathise or take a firm stand. Many of these requirements are common to the work of many customer service professionals. What makes the work of the shipping agents in particular different is the complexity of networks and relationships and interpersonal trust and rapport built up through years of experience.

Experience and trust enabled communication to go from a 10-page instruction to a quick message of 'take care of it for me' (A2). Anyone entering this world was felt to 
have a heavy learning curve for six or eight months and although there were long training periods this was considered to be no substitute for experience and building up contacts. 'There's an awful lot of experience in the job as opposed to training' (A1). Shipping is dynamic and ever changing but proving ones capabilities and knowledge enabled trust and cooperation. This store of goodwill and shared understanding helped people work together should problems go wrong. Personal knowledge of people and how they would react, dealing with the same principals or crews, all assisted the reading and interpretation of situations and emotion.

It's a lot easier when on a face-to-face basis, if you know the captain and you've met him before. (A4)

You get to know the crew and officers and you go on (the ship) and you chit chat ... Because they know the port and customs - that makes a big difference. (A5)

If the people you are dealing with know you and trust you they are much more accepting of your thoughts, plans or proposals. (P8)

We've seen the value of cultivating that very, very close trust, friendship relationships with them - so as those barriers come down ... we really work cooperatively. (P9)

The downside of everyone being connected was that if a person ever made a mistake ‘it hurts credibility ... and reputation' (P9).

\section{Interpreting Emotion across Nationalities}

All those interviewed dealt with a wide range of people and 'just to add a bit of excitement you are dealing with all different nationalities' (A2). Picking up emotion and responding to emotion in communication brings challenges. Does this pose additional challenges across nationalities and how are such skills accomplished? To carry out their job effectively respondents had to be very skilled at picking up on and interpreting emotion. So how was this complex skill acquired and accomplished?

It's just a feeling, yes it is experience, it is ... but then again you can't generalise obviously because personalities being what they are. (A1)

[Nationality] are easier to communicate with once you have met them face-toface and that makes future communication ... on a ... a bit more of a friendly basis. The email correspondence that we have with our principals in [Nation] with whom we have not met in the same company and with representatives in North America tends to take a slightly different tone ... more friendly. (A3)

They [Nationalities] each have their own little quirks ... they can be very sensitive if not approached properly. (P6)

The above quotations underscore the emotional sensitivity of respondents and start to suggest how the complex process of understanding emotion is accomplished across nationalities. Experience gained over time or by asking advice is extremely important but forms only the basic grounding in much the same way as knowing the technical 
regulations to perform their job. Generalisations and appreciating subtle differences in perhaps ways of doing business and 'just accepting that [different practices] the way it is' (P8) was only helpful in understanding emotion at a very basic level. It formed a necessary but taken-for-granted starting point. Getting to know the person, building relationships, trust and understanding their personality was far more fruitful. Dealing with different nationalities 'represent a unique challenge' (P9) and added to the rich emotional satisfaction respondents gained from their work. Respondents had a genuine desire and interest in getting to know, understand and help their customers. Dealing the first few times with a different country could pose challenges but the interviews reveal the keenness to understand other people's perspectives and build collaborative relationships.

... mainly our fault that we haven't quite been able to see things from their viewpoint ... totally ... Is it because they don't want to respond because they want you to make the decision. (A3)

Owners and crew, regardless of nationality, shared the basic perception of information required and procedures. Understanding what was being said, as opposed to interpreting any message, was a minor issue and simply resolved by asking for clarification or asking to repeat. Some communication could be 'tough to understand ... verbally' (P6) but with experience became a taken for granted skill. Respondents appreciated fully the importance of building rapport and shared understand and went out of their way to make that happen. Longevity in post and dealing with repeat customers meant respondents felt they knew the person, even if they had never met. Respondents deliberately put effort into improving understanding those who were geographically remote from them through choice and enjoyed doing so.

Once again, the way in which emotion was detected was largely by experience and 'generally tone tells the story' (P9). With 'seasoned business people' who were described as 'pretty receptive to customer issues, communication and customers' interpreting emotion proved no difficulty.

But you will know this only after you deal with the people, you deal with these particular people otherwise you will not know. But that's from experience. (S10)

\section{CONCLUSION}

The service relationship explored in this study was one where a highly complex yet seamless service was being offered and one where the potential for problems, mishaps or the unexpected happening was high. The meaning and significance of emotion in this service relationship is quite different to that of standardised, mass consumption service encounters. In the present context, emotion is far more than a match between perceived and actual service on the part of consumers. The social interaction and accomplishment of tasks through service networks engendered positive feelings of emotion in respondents. It contrasts with the view of emotions being potentially irrational and disruptive if not managed or scripted by management in the interests of organisational goals. Here there was no conflict between the interests of 
'management', 'service providers' and 'customers'. Service providers build up and maintained relationships with customers through mutual trust, understanding and cooperation. A highly routinised, scripted service would be anathema in this environment. Authentic expression of emotion came through knowing individuals and organisations. Participants were dealing with people and organisations they cared about as opposed to anonymous individuals. The customised, personal service they were offering stands in stark contrast to that engineered by centralisation of services. Personalised service extending to personal knowledge and working relationships with the ships crew, principal or shipping line was extremely important in this setting. It was a key factor leading to repeat business and maintaining emotional satisfaction for all parties.

The emotion inherent in the work did impact on service providers. Occasionally felt mood differed from that which respondents were able to display and they had to suppress their own feelings while caring for or managing the emotions of others. Being blamed for something which was not their fault, for instance, could require them to be diplomatic and appeasing. Even in such instances, they usually felt real empathy for customers and appreciated their perspective. While service providers had many years of experience to draw on, so too did their customers. This shared understanding led to a realistic expectation of what could be required and expected and of the incidents outside the control of other parties. By and large, when the customer was upset or annoyed they themselves were affected by the emotion. Not being able to help was an unpleasant feeling, as they wanted to create positive and cooperative work relationships. Respondents in this area of work genuinely did care about their customers. Research in emotion has tended to consign 'caring professions' to 'female' jobs stereotypically associated with occupations such as nursing. By contrast, the shipping world is predominantly male oriented and all but one of the respondents interviewed was male. The description of the work involving long, unsociable or flexible hours and with rates of pay being not particularly good does strike a cord with stereotypical caring professions.

The communication channel respondents chose to use to sort out problems was no surprise. Personal contact by telephone or face-to-face if feasible, was selected to confront and smooth over any upset one was causing or unable to rectify with those that one had built up good working relationships and rapport. The emotional sensitivity and awareness of respondents was underscored by how they discussed the interpretation of emotion across nationalities. They knew there was no substitute for truly caring, personal knowledge and good working relationships in understanding and responding to emotion.

The contribution of the present study to knowledge concerning service encounters is twofold. First, through the focus on business-to-business encounters as opposed to the customer-service provider interface. Service encounters in business-to-business settings are significantly different from most customer-service interfaces due to a higher appreciation of each other's work environment, pressures and constraints. The 'product' of business-to-business service encounters as revealed in this study is drawing to a successful conclusion a complex, multi-faceted operation involving many parties. The dynamics of what constitutes a successful service encounter in this context is totally different from the paradigms used to assess customer-service 
provider encounters. Dimensions such as meeting or surpassing service expectations are less appropriate in comparison to successful outcomes. Second, the study resonates with the small but growing literature arguing that emotion work, particularly emotion work involving autonomy and job involvement, has positive consequences for employees. The picture of emotional labour, driven by those in positions of dominance to meet organisational goals with largely negative consequences for employees, is directly challenged. In this context, all parties shared 'organisational' goals.

The study suggests several areas for future research. In relation to the area of service skills, it suggests further research into the growing complexity of service relationships involving networks of different parties providing a seamless service. The artisan nature of the present study, with long service personnel steeped in the shipping environment, raises issues for the future, as working patterns are changing. How customer service agents acquire and share tacit knowledge with others, particularly in times of rapid change and where long service is unusual, needs a clearer articulation. In sectors where service agents are physically located together tacit knowledge may be informally shared but there is a growing trend towards outsourcing and home working. Trust and confidence is built over time, but the complex ways in which emotion shapes confidence and trust and vice versa is still veiled. The literature is still largely silent on how customer service agents in business-to-business relationships move from superficial understanding of emotions to a deeper appreciation of their significance, particularly in cross-national settings. The relative balance between technical knowledge and interpersonal competencies and the interaction and impact of these areas on emotions in business-to-service relationships would benefit from future exploration.

\section{ACKNOWLEDGEMENTS}

I would like to thank the Canadian High Commission and Department of External Affairs \& International Trade, Ottawa, Canada for supporting the research through a Canadian Studies Faculty Research Award. I am also extremely grateful to participants who made this study possible: Shipping Agents and Shipping Lines in Vancouver, Canada and Poole, UK, Vancouver Port Authority and Poole Harbour Commission.

\section{REFERENCES}

Armistead, C., Beamish, N. and Kiely, J. (2001) Evolution of the Customer Service Professional: Future Roles and Capabilities, London: Institute of Customer Service.

Ashforth, B.E. and Humphrey, R.H. (1995) Emotion in the workplace: a reappraisal, Human Relations, 48(2), pp. 97-125.

Bagozzi, R., Gopinath, M. and. Nyer, P. (1999) The role of emotions in marketing, Journal of the Academy of Marketing Science, 27(2), pp. 184-206.

Broderick, A.J. (1999) Role theory and the management of service encounters, The Service Industries Journal, 19(3), pp. 117-31.

Davie, M., Stankov, L. and Roberts, R. (1998) Emotional intelligence: in search of an elusive construct, Journal of Personality and Social Psychology, 75(4), pp. 989-1015. 
Domagalski, T.A. (1999) Emotion in organizations: main currents, Human Relations, 52, pp. 833-52.

Edwards, D. (1999) Emotion discourse, Culture and Psychology, 5(3), pp. 271-91.

Eisenberg, R., Fabes, R., Guthrie, I. and Reiser, M. (2000) Dispositional emotionality and regulation: their role in predicting quality of social functioning, Journal of Personality and Social Psychology, 78(1), pp. 136-57.

Fineman, S. (1993) Emotion in Organizations, London: Sage.

Fineman, S. (1996) Emotion and organizing. In S. Clegg, C. Hardy and W. Nord (eds), The Handbook of Organization Studies, Thousand Oaks, CA: Sage, pp. 543-64.

Fineman, S. (1999) The emotion of control: a qualitative exploration of environmental regulation, Human Relations, 52, pp. 631-63.

Goleman, D. (1995) Emotional Intelligence: Why it Can Matter More than IQ, New York: Bantam Books.

Goleman, D. (1998) Working with Emotional Intelligence, New York: Bantam Books.

Gronroos, C. (1984) A service quality model and its marketing implications, European Journal of Marketing, 18(4), pp. 36-45.

Gutek, B.A., Bhappu, A.D., Liao-Troth, M.A. and Cherry, B. (1999) Distinguishing between service relationships and encounters, Journal of Applied Psychology, 84(2), pp. 218-33.

Hatfield, E., Cacioppo, J.T. and Rapson, R.L. (1994) Emotional Contagion, Paris: Cambridge University Press.

Hochschild, A.R. (1983) The Managed Heart, Berkeley and Los Angeles, CA: University of California Press.

Johnson, R. and Clark, G. (2001) Service Operations Management, Harlow: Prentice-Hall/Pearson Education.

Kemper, T.D. (1978) A Social Interaction Theory of Emotion, New York: John Wiley and Sons.

Kruml, S.M. and Geddes, D. (2000) Exploring the dimensions of emotional labor, Management Communication Quarterly, 14(1), pp. 8-49.

Kunda, G. (1992) Engineering Culture: Control and Commitment in a High-Tech Corporation, Philadelphia, PA: Temple University Press.

Leidner, R. (1991) Selling hamburgers and selling insurance: gender, work and identity in interactive service jobs, Gender and Society, 5(2), pp. 154-77.

Liljander, V. and Strandvik, T. (1996) Emotions in service satisfaction, International Journal of Service Industries Management, 8(2), pp. 148-69.

Locke, K. (1996) A funny thing happened! The management of consumer emotions in service encounters, Organizational Science, 7(1), pp. 40-59.

Morris J. and Feldman, D. (1996) The dimensions, antecedents, and consequences of emotional labor, Academy of Management Review, 21, pp. 986-1010.

Mano, H. and Oliver, R. (1993) Assessing the dimensionality and structure of the consumption experience, feeling and satisfaction, Journal of Consumer Research, 20, pp. 451-66.

Oliver, R.L. (1993) Cognitive, affective and attribute bases of the satisfaction response', Journal of Consumer Research, 20, pp. 418-30.

Menon, K and Dube, L. (2000) Ensuring greater satisfaction by engineering salesperson response to customer emotions, Journal of Retailing, 76(3), pp. 285-308.

Parasuraman, A., Zeithaml, V.A. and Berry, L.L. (1985) A conceptual model of service quality and its implications for future research, Journal of Marketing, 49, pp. 41-50.

Parasuraman, A., Zeithaml, V.A. and Berry, L.L. (1988) SERVQUAL: a multiple-item scale for measuring consumer perceptions of service quality, Journal of Retailing, 64, pp. 12-40.

Parkin, W. (1993) The public and the private: gender, sexuality and emotion. In S. Fineman (ed.), Emotion in Organizations, London: Sage, pp. 167-89.

Parkinson, B. (1995) Ideas and Realities of Emotions, New York: Routledge.

Price, L.L., Arnould, E.J. and Deibler, S. (1995) Consumers emotional responses to service encounter: the influence of the service provider, International Journal of Service Industries Management, 3, pp. 34-63.

Rafaeli, A. and Sutton, R.I. (1989) The expression of emotion in organisational life, Research in Organizational Behaviour, 11, pp. 1-42.

Richins, M. (1997) Measuring emotions in the consumption experience, Journal of Consumer Research, 24(2), pp. 127-46.

Schaubroeck, J. and Jones, J.R. (2000) Antecedents of workplace emotional labor dimensions and moderators of their effects on physical symptoms, Journal of Organizational Behaviour, 21, pp. 163-83.

Steinberg, R.J. and Figart, D.M. (1999) Emotional labour since The Managed Heart, The Annals of the American Academy, 561, pp. 8-26. 
Strauss, B. and Neuhaus, P. (1997) The qualitative satisfaction model, International Journal of Service Industries Management, 8(3), pp. 236-49.

Strazdins, L.M. (2000) Integrating emotions: multiple role measurement of emotional work, Australian Journal of Psychology, 52(1), pp. 41-50.

Sturdy, A., Grugulis, I. and Willmott, H. (2001) Customer Service: Empowerment and Entrapment, Critical Perspectives on Work and Organisations Series, Basingstoke: Macmillan.

Yu, Y. and Dean, A. (2001) The contribution of emotional satisfaction to consumer loyalty, International Journal of Service Industries Management, 12(3), pp. 234-50.

Van Dolen, W., Lemmink, J., Mattsson, J. and Rhoen, I. (2001) Affective consumer responses in service encounters: the emotional content in narratives of critical incidents, Journal of Economic Psychology, 22, pp. 359-76.

Wharton, A.S. (1993) The affective consequences of service work: managing emotions on the job, Work and Occupations, 20(2), pp. 205-32.

Wharton, A.S. and Erickson, R.J. (1995) The consequences of caring: exploring the link between women's job and family emotion work, The Sociological Quarterly, 36, pp. 273-96.

Woodruffe, C. (2001) Promotional intelligence, People Management, 11 January, pp. 26-9.

Zeithaml, V.A., Berry, L.L. and Parasuraman, A. (1993) The nature and determinants of customer expectation of service, Journal of the Academy of Marketing Science, 21(1), pp. 1-12. 